\title{
Quantitative Continuous EEG: Bridging the Gap Between the ICU Bedside and the EEG Interpreter
}

\author{
Andreas H. Kramer ${ }^{*}$ (i) and Julie Kromm
}

@ 2019 Springer Science+Business Media, LLC, part of Springer Nature and Neurocritical Care Society

Non-convulsive seizures (NCSZs) and non-convulsive status epilepticus (NCSE) are common in critically ill patients and are associated with neurophysiologic disturbances, mortality, and worsened recovery [1-7]. Continuous electroencephalography (cEEG) is required to detect NCSZs, but at most centers, tracings can only be intermittently reviewed by neurophysiologists a few times per day, primarily during day-time hours [8]. Multidisciplinary professionals who are at the bedside caring for critically ill patients usually do not have specific proficiency in EEG interpretation, while neurophysiologists infrequently have critical care expertise and commonly interpret cEEG tracings remotely rather than at the bedside. Although a growing number of neurointensivists have at least some EEG training, additional strategies are needed to better integrate cEEG information into patient care and to bridge the gap between bedside providers and neurophysiologists, thereby ensuring that appropriate treatment is delivered in a timely fashion.

Quantitative cEEG consists of visually simplified, timecompressed displays summarizing various elements of electrographic data (frequencies, amplitude, power, and rhythmicity), allowing interpreters to see, in effect, "the forest" rather than "the trees" [9]. Interpreters can screen large amounts of data much more efficiently than by reviewing the entire raw cEEG tracing $[10,11]$. For example, in the $8 \mathrm{~h}$ of quantitative cEEG data shown in Fig. 1, there is little change between 12:00 and 18:00, such that less time can be spent reviewing the raw EEG obtained during these hours.

*Correspondence: Andreas.Kramer@AlbertaHealthServices.ca Departments of Critical Care Medicine and Clinical Neurosciences, Hotchkiss Brain Institute, University of Calgary, Calgary, Canada
Electrographic seizures are characterized by the onset of rhythmic epileptiform discharges that usually evolve in frequency, morphology, and location $[4,12]$. In many cases, these transient changes can be observed without difficulty using quantitative displays. In Fig. 1, reviewers' attention would be immediately drawn to the abrupt and brief alterations in EEG frequencies and power beginning at about 18:00. Each of the subsequent "events" in the panel coincides with an electrographic seizure (these are magnified in Fig. 2 by shortening the epoch to $4 \mathrm{~h}$ ).

The previous literature has assessed the diagnostic accuracy of quantitative EEG displays in comparison with the gold standard of raw cEEG interpreted by board-certified neurophysiologists (Table 1) [10, 11, 13-22]. Color density spectral array (CDSA) and amplitude integrated EEG (aEEG) are the quantitative modalities that have been best studied, while a proprietary "rhythmicity spectrogram" has become available more recently and has not been studied as extensively (Figs. 1 and 2). For neurophysiologists, the main advantage of quantitative displays is in saving time during cEEG interpretation $[10,11]$. For critical care physicians and nurses, the primary purpose is in recognizing transient alterations in the cEEG tracing that could alert them to the presence of seizures. The sensitivity of quantitative displays has been reported to be in the range of $65-90 \%$ and does not appear to differ significantly based on the expertise of the interpreter, or when CDSA and aEEG are compared. Seizures may be missed, especially if they are low in amplitude, low in frequency, focal, or have other characteristics that prevent them from standing out compared to the EEG background.

A variety of non-ictal EEG patterns (e.g., periodic discharges, artifact related to patient movement, or state changes) may be indistinguishable from seizures using quantitative cEEG displays, such that suspicious time

\section{勿




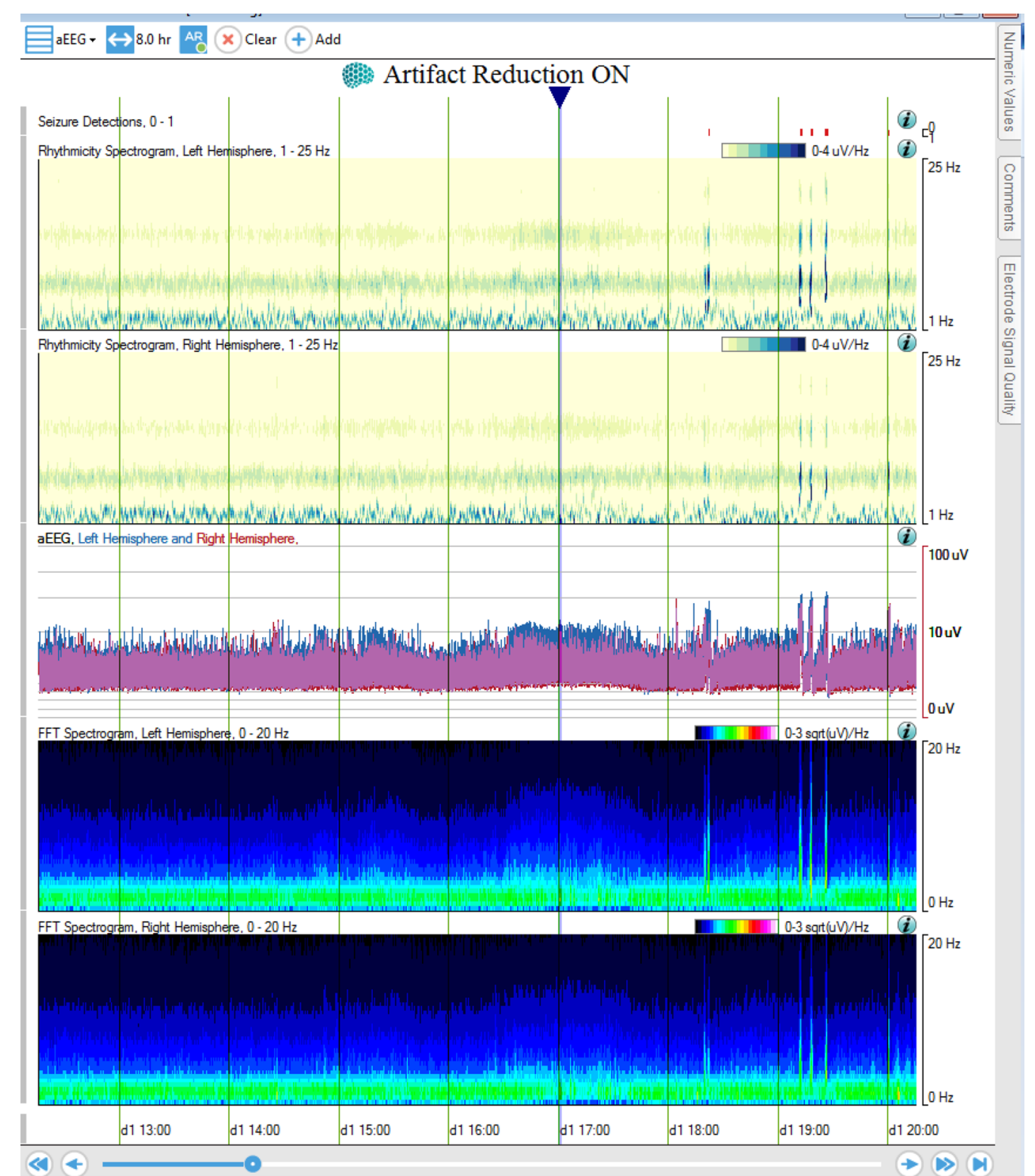

Fig. 1 Eight-hour quantitative EEG panel (rhythmicity spectrogram, aEEG, and CDSA) from 33-year-old patient with viral encephalitis complicated by non-convulsive status epilepticus. Beginning at 18:00, there are multiple events with rhythmicity and increased EEG amplitude and frequency. Raw EEG confirmed that these were electrographic seizures

periods should always be assessed using the raw cEEG tracing before prompting changes in management (Fig. 3). In several studies, false positives are common, especially among non-experts, who also generally do not have the advantage of being able to correlate the quantitative tracing with the corresponding raw cEEG. For example, a recent study found as many as $7-8$ false positive "seizures" per $24 \mathrm{~h}$ when quantitative displays were reviewed by pediatric intensive care unit (ICU) fellows [19]. Another study reported a specificity of only $38 \%$ when tracings were interpreted by ICU nurses [22]. Inappropriate treatment of false positives could potentially cause complications and increased ICU length of stay. Conversely, if ICU professionals call a neurophysiologist for each false positive, it may become overly burdensome and non-sustainable. Thus, even if quantitative displays are used, it is helpful for ICU physicians and nurses to develop at least some proficiency in EEG interpretation, especially to rule out seizures when quantitative cEEG changes are obviously due to artifact. The previous 


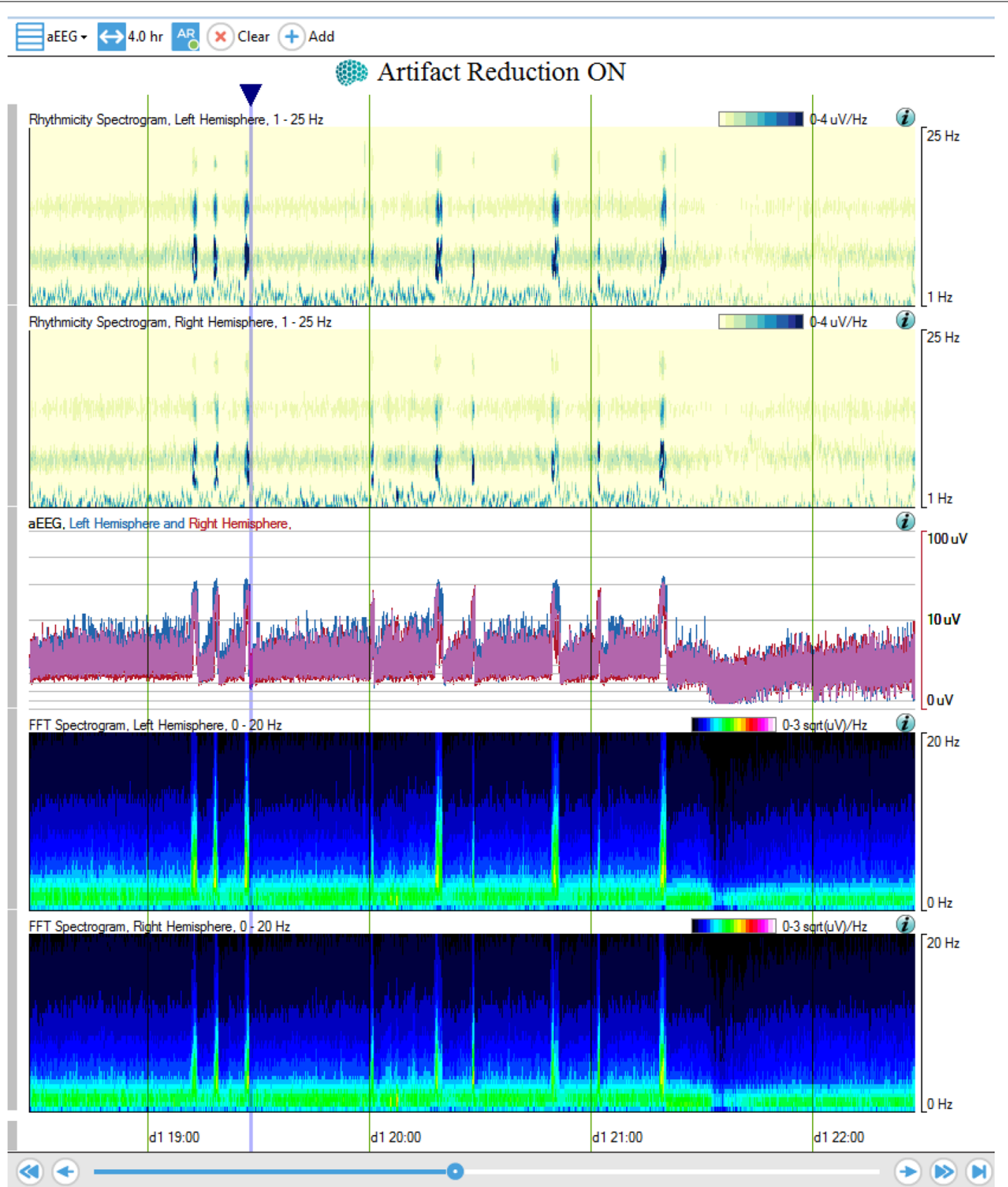

Fig. 2 Four-hour quantitative EEG panel of same patients as Fig. 1 (right), showing changes attributable to multiple NCSZs. After each seizure, the patient received a bolus dose of a sedative followed by an increment in the infusion rate. NCSZs were abolished shortly after 21:00 with a combination of propofol $(50 \mu \mathrm{g} / \mathrm{kg} / \mathrm{min})$ and ketamine $(3 \mathrm{mg} / \mathrm{kg} / \mathrm{h})$ infusions

literature has shown the feasibility of training neurocritical care nurses to recognize electrographic seizures on raw EEG, but further research is needed to demonstrate generalizability [23].

In patients with NCSE, the electrographic characteristics of individual NCSZs are usually fairly characterized. Consequently, the quantitative EEG tracings tend to be similar from one seizure to the next. In practice, a neurophysiologist can therefore instruct bedside clinicians regarding what specifically to look for as they monitor the patient over the subsequent hours. In this way, therapy can be rapidly titrated to achieve seizure control, even without continuous presence or availability of a neurophysiologist (Fig. 2) [24].

In this volume of neurocritical care, Kang and colleagues have contributed to the literature by performing a prospective study where quantitative EEG was utilized at the bedside by ICU nurses (rather than in a 
Table 1 Studies assessing the diagnostic accuracy of quantitative continuous electroencephalography in neurocritical care patients (excluding neonates)

\begin{tabular}{|c|c|c|c|c|c|c|}
\hline Study & $\begin{array}{l}\text { Number } \\
\text { tracings }\end{array}$ & Setting & Interpreters & Type of display & Sensitivity & Specificity \\
\hline Stewart [13] & 27 & PICU & Neurophysiologists & 8-h CDSA and aEEG & $\begin{array}{l}83 \% \text { CDSA } \\
82 \% \text { aEEG }\end{array}$ & $\begin{array}{l}\text { FP: } 0-0.13 / \mathrm{h} \text { CDSA } \\
\text { FP: } 0-0.19 / \mathrm{h} \text { aEEG }\end{array}$ \\
\hline $\begin{array}{l}\text { Moura [10] } \\
\text { Williamson [21] }\end{array}$ & 118 & $\begin{array}{l}\text { Adults (ICU and non- } \\
\text { ICU) }\end{array}$ & Neurophysiologists & 2-h CDSA & $87-89 \%$ & NR \\
\hline Pensirikul [14] & 21 & $\mathrm{PICU}$ & Neurophysiologists & $2-h$ CDSA & $65-75 \%$ & $78-92 \%$ \\
\hline Topjian [15] & 100 & PICU (cardiac arrest) & $\begin{array}{l}\text { ICU MDs } \\
\text { ICU fellows } \\
\text { ICU RNs }\end{array}$ & 2-h CDSA & $70 \%$ & $68 \%$ \\
\hline Dericioglu [16] & 20 & $\mathrm{AlCU}$ & $\begin{array}{l}\text { ICU fellows } \\
\text { ICU RNs }\end{array}$ & 1-h CDSA and aEEG & $88-99 \%$ & $89-95 \%$ \\
\hline Swisher [17] & 180 & $\mathrm{AICU}$ & $\begin{array}{l}\text { Neurophysiologists } \\
\text { EEG technologists } \\
\text { ICU RNs }\end{array}$ & $\begin{array}{l}\text { 1-h CDSA, aEEG } \\
\text { Rhythmicity spectro- } \\
\text { grams } \\
\text { EEG asymmetry index }\end{array}$ & $80-87 \%$ & $61-80 \%$ \\
\hline Haider [11] & 15 & $\mathrm{AICU}$ & Neurophysiologists & $\begin{array}{l}\text { 6-h CDSA and aEEG } \\
\text { Rhythmicity spectro- } \\
\text { grams } \\
\text { Envelope trend }\end{array}$ & $67 \%$ & FP: $1 / h$ \\
\hline $\begin{array}{l}\text { Du Pont-Thibodeau } \\
\text { [18] }\end{array}$ & 100 & PICU (cardiac arrest) & $\begin{array}{l}\text { ICU MDs } \\
\text { ICU fellows } \\
\text { ICU RNs }\end{array}$ & $\begin{array}{l}\text { 2-h aEEG + CDSA } \\
\text { tracings }\end{array}$ & $\begin{array}{l}77 \% \mathrm{aEEG} \\
77 \% \mathrm{aEEG}+\mathrm{CDSA}\end{array}$ & $\begin{array}{l}65 \% \mathrm{aEEG} \\
68 \% \mathrm{aEEG}+\mathrm{CDSA}\end{array}$ \\
\hline Lalgudi Ganesan [19] & 27 & PICU & $\begin{array}{l}\text { ICU fellows } \\
\text { ICU RNs } \\
\text { Neurophysiologists } \\
\text { EEG technologists }\end{array}$ & 8-h CDSA and aEEG & $\begin{array}{l}73-88 \% \text { CDSA } \\
67-84 \% \text { aEEG }\end{array}$ & $\begin{array}{l}\text { FP: } 0-7.7 / 24 \text { h CDSA } \\
\text { FP: } 0-4.2 / 24 \text { h aEEG }\end{array}$ \\
\hline Sun [20] & 30 & $\mathrm{AICU}$ & Neurophysiologists & 24-h CDSA and aEEG & $\begin{array}{l}80 \% \text { CDSA } \\
81 \% \text { aEEG }\end{array}$ & $\begin{array}{l}F P: 4 / 24 h \text { CDSA } \\
F P: 2 / 24 h \text { aEEG }\end{array}$ \\
\hline Amorim [22] & 49 & $\mathrm{AlCU}$ & $\begin{array}{l}\text { ICU RNs } \\
\text { Neurophysiologists }\end{array}$ & 2-h CDSA & $\begin{array}{l}74 \% \text { RN } \\
66 \% \text { neurophysiolo- } \\
\text { gists }\end{array}$ & $\begin{array}{l}38 \% \text { RNs } \\
69 \% \text { neurophysiolo- } \\
\text { gists }\end{array}$ \\
\hline
\end{tabular}

aEEG amplitude integrated EEG, AICU adult intensive care unit, CDSA color density spectral array, FP false positives, $M D$ medical doctor, $P I C U$ pediatric ICU, $R N$ registered nurse

simulated post hoc setting). Nurses received individualized, patient-specific quantitative EEG instructions while caring for their patients, with examples provided of what CDSA, aEEG, and rhythmicity spectrogram tracings had looked like during previous seizures. With this pragmatic approach, nurses' diagnostic accuracy in the recognition of subsequent seizures was excellent, with a sensitivity of $85 \%$, specificity of $89 \%$ (approximately one false positive every $10 \mathrm{~h}$ ), and a high rate of interobserver agreement. As in previous studies, seizures were more consistently recognized when they were topographically more extensive and of longer duration.

Even with an excellent educational strategy, it is likely not realistic for most large and busy ICUs to educate all of their nursing staff in the competent and consistent recognition of electrographic seizures. In contrast, providing patient-specific quantitative EEG instructions at the onset of cEEG monitoring is more feasible. The main limitation of the work by Kang and colleagues is that it applies only to a subset of patients, namely those admitted to the ICU with status epilepticus, where previous electrographic seizures have been observed. It is unlikely that this approach would be as accurate if comatose patients, in whom no previous seizures have been detected and who are less likely to develop seizures at all, undergo cEEG monitoring. Also, the average length of data collection was only $8 \mathrm{~h}$. In every-day practice, the quality of EEG tracings tends to deteriorate over time due to patient movement and diaphoresis, such that the potential for false positives and false negatives due to EEG artifact also increases, especially if EEG technologists are unavailable to assist with electrode re-application. These considerations likely explain the higher specificity observed by Kang and colleagues in comparison with the previous research involving ICU nurses [18, $19,22]$.

Virtually all of the published studies to date have selection bias as an important limitation, since they generally do not involve an unfiltered, consecutive sample of patients and cEEG tracings in a "real-life" setting. 

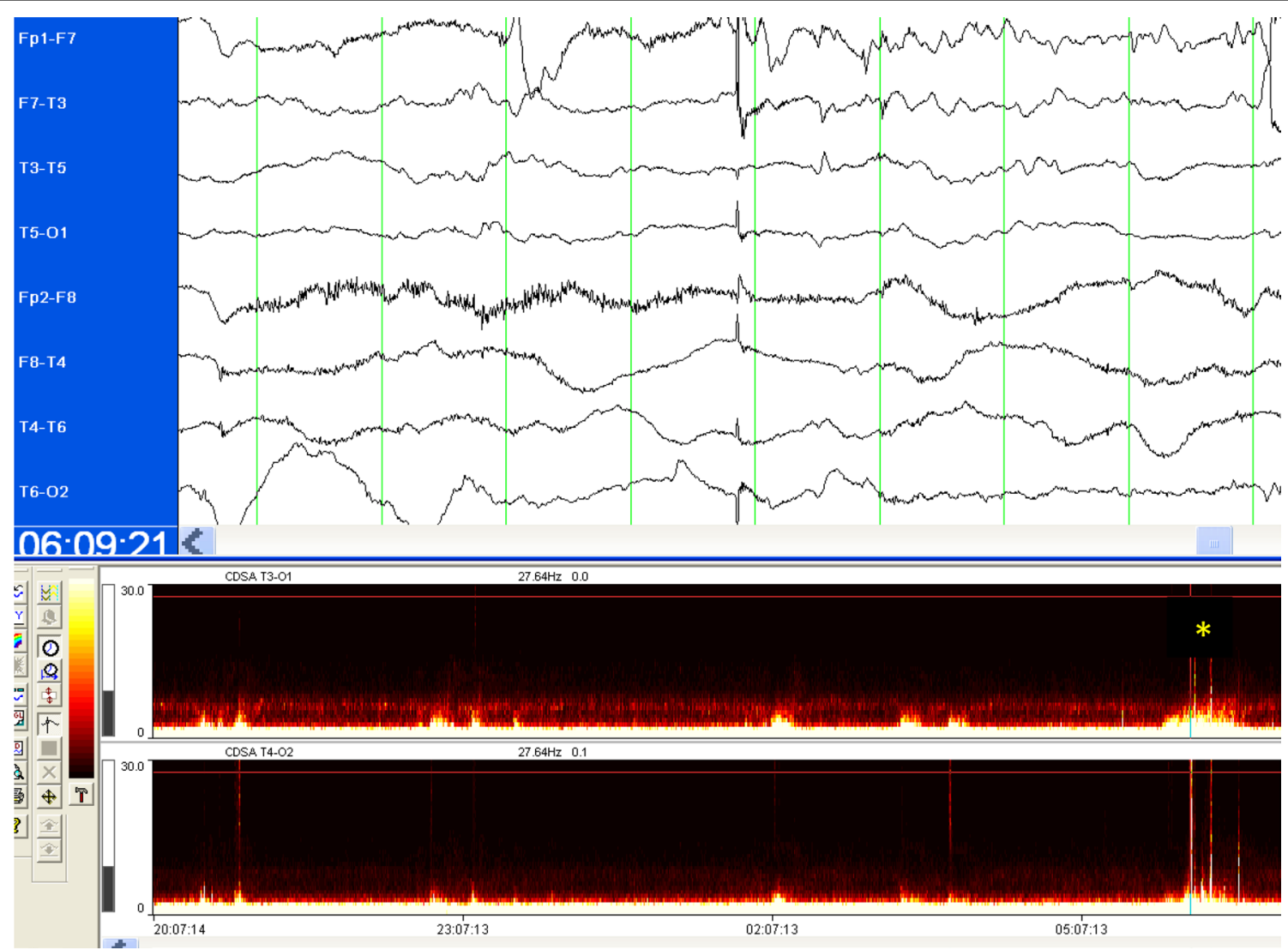

Fig. 3 Sudden change in quantitative CDSA tracing (raw EEG corresponds in time to asterisk) caused by EEG artifact while patient was being suctioned. The preceding paroxysmal alterations seen on the CDSA tracing (bottom of figure) were induced by frontal intermittent rhythmic delta activity (FIRDA; corresponding raw EEG not shown) rather than electrographic seizures

In order to advance this field further, more prospective studies of consecutive quantitative cEEG are required, including among patients not necessarily known in advance to have repeated, electrographically similar seizures. Future research should also pursue methods of improving quantitative cEEG detection of focal, lowamplitude, and relatively brief seizures.

In summary, Kang and colleagues have prospectively validated a practical approach in an important subgroup of patients. This methodology can easily be applied at any center that uses cEEG monitoring and has access to quantitative software.

\section{Author Contributions}

Dr. Kramer wrote the first draft, edited, and approved the manuscript. Dr. Kromm edited and approved the manuscript.

\section{Source of Support}

No funding.

\section{Conflict of interest}

The authors declare that they have no conflict of interest.

\section{Publisher's Note}

Springer Nature remains neutral with regard to jurisdictional claims in published maps and institutional affiliations.

Published online: 20 February 2019

\section{References}

1. Claassen J, Mayer SA, Kowalski RG, et al. Detection of electrographic seizures with continuous EEG monitoring in critically ill patients. Neurology. 2004;62:1743-8.

2. Oddo M, Carrera E, Claassen J, et al. Continuous electroencephalography in the medical intensive care unit. Crit Care Med. 2009;37:2051-6.

3. Kramer AH, Jette $\mathrm{N}$, Pillay $\mathrm{N}$, et al. Epileptiform activity in neurocritical care patients. Can J Neurol Sci. 2012;39:328-37.

4. Young GB, Jordan KG, Doig GS. An assessment of nonconvulsive seizures in the intensive care unit using continuous EEG monitoring: an investigation of variables associated with mortality. Neurology. 1996;47:83-9.

5. Claassen J, Perotte A, Albers D, et al. Nonconvulsive seizures after subarachnoid hemorrhage: multimodal detection and outcomes. Ann Neurol. 2013;74:53-64.

6. Vespa PM, Miller C, McArthur D, et al. Nonconvulsive electrographic seizures after traumatic brain injury result in a delayed, prolonged increase in intracranial pressure and metabolic crisis. Crit Care Med. 2007;35:2870-6. 
7. Vespa PM, McArthur DL, XuY, et al. Nonconvulsive seizures after traumatic brain injury are associated with hippocampal atrophy. Neurology. 2010;75:792-8

8. Gavvala J, Abend N, LaRoche S, et al. Continuous EEG monitoring: a survey of neurophysiologists and neurointensivists. Epilepsia. 2014;55:1864-71.

9. Scheuer ML, Wilson SB. Data analysis for continuous EEG monitoring in the ICU: seeing the forest and the trees. J Clin Neurophysiol. 2004;21:353-78.

10. Moura $L$, Shafi MM, Ng M, et al. Spectrogram screening of adult EEGs is sensitive and efficient. Neurology. 2014;83:56-64

11. Haider HA, Esteller R, Hahn CD, et al. Sensitivity of quantitative EEG for seizure identification in the intensive care unit. Neurology. 2016;87:935-44.

12. Chong DJ, Hirsch LJ. Which EEG patterns warrant treatment in the critically ill? Reviewing the evidence for treatment of periodic epileptiform discharges and related patterns. J Clin Neurophysiol. 2005;22:79-91.

13. Stewart $C P$, Otsubo $H$, Ochi $A$, et al. Seizure identification in the ICU using quantitative EEG displays. Neurology. 2010;75:1501-8.

14. Pensirikul AD, Beslow LA, Kessler SK, et al. Density spectral array for seizure identification in critically ill children. J Clin Neurophysiol. 2013;30:371-5.

15. Topjian AA, Fry M, Jawad AF, et al. Detection of electrographic seizures by critical care providers using color density spectral array after cardiac arrest is feasible. Pediatr Crit Care Med. 2015;16:461-7.

16. Dericioglu N, Yetim E, Bas DF, et al. Non-expert use of quantitative EEG displays for seizure identification in the adult neuro-intensive care unit. Epilepsy Res. 2015;109:48-56.
17. Siwsher CB, White CR, Mace BE, et al. Diagnostic accuracy of electrographic seizure detection by neurophysiologists and non-neurophysiologists in the adult ICU using a panel of quantitative EEG trends. J Clin Neurophysiol. 2015;32:324-30.

18. Du Pont-Thibodeau G, Sanchez SM, Jawad AF, et al. Seizure detection by critical care providers using amplitude-integrated electroencephalography and color density spectral array in pediatric cardiac arrest patioents. Pediatr Crit Care Med. 2017;18:363-9.

19. Lalgudi Ganesan S, Steward CP, Atenafu EG, et al. Seizure identification by critical care providers using quantitative electroencephalography. Crit Care Med. 2018;46:e1105-11.

20. Sun J, Ma D, Lv Y. Detection of seizure patterns with multichannel amplitude-integrated EEG and the color density spectral array in the adult neurology intensive care unit. Medicine. 2018;97:e12514.

21. Williamson CA, Wahlster S, Shafi M, Westover MB. Sensitivity of compressed spectral arrays for detecting seizures in acutely ill adults. Neurocrit Care. 2014;20:32-9.

22. Amorim E, Williamson CA, Moura L, et al. Performance of spectrogrambased seizure identification of adult EEGs by critical care nurses and neurophysiologists. J Clin Neurophysiol. 2017:34:59-64.

23. Seiler $L$, Fields J, Peach $E$, et al. The effectiveness of a staff education program on the use of continuous EEG with patients in neuroscience intensive care units. J Neurosci Nurs. 2012;44:E1-5.

24. Kramer $\mathrm{AH}$. Early ketamine to treat refractory status epilepticus. Neurocrit Care. 2012;16:299-305 